\title{
Acerca de la cronología de la epigrafía Vadiniense. Revisión historiográfica y nuevas propuestas
}

\author{
About the chronology of the Vadinienses epigraphy. \\ Historiographical review and new proposals
}

\author{
David MARTINO GARCIA*
}

\begin{abstract}
RESUMEN
El presente trabajo trata sobre el problema de la cronología de las inscripciones romanas del pueblo cántabro de los vadinienses. Tras una revisión de la historiografía, se presenta una nueva propuesta de datación de todas las inscripciones funerarias vadinienses ofreciendo nuevos criterios para definir su cronología. Esta nueva propuesta aumenta el número de epígrafes datados en el siglo I d.C., y se afirma que la mayoría corresponden al siglo II d.C.
\end{abstract}

\section{PALABRAS CLAVE}

Epigrafía romana, Cantabri, Vadinienses, Cronología.

\begin{abstract}
This paper deals with the problem of the Roman inscriptions chronology's of the Vadinienses Cantabrian people. After a review of historiography, a new dating of all epitaphs vadinienses is presented, offering new criteria to define its chronology. This new proposal increases the number of entries dating from the first century A.D, and affirms that the majority of them correspond to the second century A.D.
\end{abstract}

\section{KEYWORDS}

Roman epigraphy, Cantabri, Vadinienses, Chronology.

Recibido el 2 de junio de 2012. Aceptado el 9 de agosto de 2012

Es de sobra conocido que el momento de justificar la datación de una inscripción de época romana es uno de los mayores retos a los que se enfrenta el epigrafista en su labor de edición y comentario. Si esto es cierto en términos generales para cualquier ejemplar que carezca de datación explícita y para aquellos corpora de ambientes urbanos o más romanizados -entendido este concepto

* Universidad Complutense de Madrid. C/ Ordesa 10, 1 B, 19005 GUADALAJARA, dmartinogarcia@gmail.com. Agradecemos al profesor J. Gómez-Pantoja la lectura, sugerencias y enmiendas a un manuscrito de un tema tan espinoso como la datación epigráfica, pero, en todo caso, tanto las afirmaciones como los errores que con seguridad permanecen en el texto son responsabilidad mía. 
como más próximo a los usos epigráficos de las colonias o municipios romanos así como de los epígrafes erigidos por y/o para los ciudadanos romanos-, en el caso de la epigrafía de zonas rurales o periféricas del imperio con marcada impronta indígena el problema se hace aun mayor. En este trabajo abordamos la cronología de la epigrafía vadiniense, revisando en primer lugar la literatura y las dificultades metodológicas, y aportando a continuación algunos argumentos que permitan establecer nuevas hipótesis cronológicas. A la vez, esta contribución quiere servir de homenaje al insigne profesor G. Alföldy, uno de los maestros de cuyos trabajos sobre epigrafía hispana tantos y tanto hemos aprendido.

\section{PANORAMA HISTORIOGRÁFICO}

El precursor en el estudio de la cronología de los epígrafes vadinienses, al igual que para otros muchos aspectos de la epigrafía hispana, fue E. Hübner, quien en su Corpus Inscriptionum Latinarum recogió ya 29 ejemplares. Este autor se decantó siempre por los siglos I o II d.C. para los cinco epígrafes en los que justificó su cronología a partir de criterios paleográficos. Así, propuso el siglo I para los tres ejemplares con letras de buena factura: uno de Corao (Cangas de Onís) ${ }^{1}$, uno de Aleje (Crémenes) ${ }^{2}$ y otro de Valmartino (Cistierna) ${ }^{3}$. En los dos otros casos, la peor calidad de la grafía le sirve para situar ambos epígrafes en el siglo II, así en Liegos (Acebedo) ${ }^{4}$ y Beleño (Ponga) ${ }^{5}$.

Pocos años después de la publicación del Supplementum al CIL II, ya en los primeros años del siglo XX, el corpus epigráfico vadiniense creció gracias a M. Gómez Moreno que al confeccionar su Catálogo añadió otras 15 piezas inéditas ${ }^{6}$, si bien, no se detuvo en consideraciones cronológicas sobre las nuevas, ni sobre las ya conocidas. No será hasta décadas después cuando se aporte la primera datación en bloque de la epigrafía vadiniense a cargo del profesor J.M. Navascués, quien se enfrentó con detalle al problema cronológico al hilo del comentario de una estela funeraria hallada en Cármenes ${ }^{7}$. Para Navascués, la epigrafía de este populus cántabro es claramente tardía, pues consideró que en vista a la similitud de las características externas y del contenido textual de todo el corpus, se debía si-

\footnotetext{
${ }^{1}$ CIL II 2708=5730: litterae videntur esse optimae saeculi primi.

2 CIL II 5719: litterae sunt magnae saec. I.

${ }^{3}$ CIL II 5714: litterae videntur esse saeculi I.

${ }^{4}$ CIL II 5705: litteris parvis saeculi fere secundi.

${ }^{5}$ CIL II 5735: litteris rudibus sed perspicuis, saeculi fortasse secundi.

${ }^{6}$ Catálogo Monumental de España. Provincia de León (1906-1908), Madrid, pp. 40-46, especialmente pp. 43ss y pp. 83-84 para las inéditas.

7 Siempre que sea posible citaremos los epígrafes según la base de datos on-line de Hispania Epigraphica (http://eda-bea.es/), citando en adelante: HEpOL no de registro. Presenta el siguiente texto: Di(s) ma(nibus) s(acrum) m/onimen(tum) / Allae Vi/ancior(um) / At(t)i Pro(culi) / an(norum) XX / A(m)ma $m$ (ater) $s$ (ua) p(osuit) (HEpOL 19267). Si bien desde el punto de vista tipológico comparte evidentes características con el conjunto vadiniense, es un ejemplar que queda fuera del territorium de Vadinia, y por tanto no debe incluirse en sentido estricto dentro de este corpus epigráfico. Al respecto del corpus, vid.
} infra. 
tuar todo el conjunto en una misma época que él situó entre las últimas décadas del siglo II d.C. y mediados del siglo IV d.C. ${ }^{8}$ En un trabajo ligeramente posterior precisó los márgenes cronológicos estableciendo definitivamente el inicio de esta epigrafía en la segunda mitad del s. II para finalizar en la primera mitad del s. IV. ${ }^{9}$

La propuesta cronológica de Navascués ha gozado de amplia aceptación en los trabajos posteriores hasta convertirse en communis opinio. Así, por ejemplo, en el trabajo de la profesora C. García Merino ${ }^{10}$ que revisa varios de los aspectos históricos relativos a los vadinienses a propósito de una nueva inscripción. También, es seguida por T. Mañanes y M. Gómez ${ }^{11}$ en la editio princeps de varias estelas halladas en la provincia de León, por E. Marcos Vallaure ${ }^{12}$ al dar a conocer cinco nuevos epígrafes y por E. González Miguel ${ }^{13}$ en la publicación de la conocida inscripción del cives (sic) Vad(iniensis). Del mismo modo, Ma․ C. González y J. Santos también son deudores de la propuesta de Navascués en su completo y detallado trabajo sobre la problemática histórica de los vadinienses en el que incorporaban también el corpus epigráfico actualizado. En este trabajo sostenían una datación general entre fines del s. II y mediados del siglo IV, si bien resaltando que la mayoría de los epígrafes son del siglo III $^{14}$. En fin, la propuesta de Navascués es aceptada también en otros trabajos históricos ${ }^{15} \mathrm{o}$ arqueológicos ${ }^{16}$ más generales.

El descubrimiento hace pocos años de un nuevo epígrafe funerario relativo a un princeps Cantabrorum en la parte meridional del ámbito vadiniense, ha venido a replantear la cuestión de los márgenes cronológicos asignables a estas inscripciones, dado que el epígrafe del princeps se fecha, tal como veremos infra, con bastante seguridad en el siglo I d.C. ${ }^{17}$ En esta misma línea de revisión de la cronología general de la epigrafía vadiniense se ha manifestado I. Sastre en sus de-

8 «La estela funeraria de Cármenes», AEspA 43, no 120-121, (1970), pp. 191-194.

9 «Trío de estelas», Revista de la Universidad Complutense (Homenaje a Gómez Moreno) 8 , (1972), p. 175.

${ }_{10}$ «Nuevo epígrafe vadiniense, procedente de Carande (León), y el problema de los vadinienses como grupo de población hispanorromano», BSAA, 38, (1972), p. 506.

11 «De epigrafía leonesa. Nuevas inscripciones vadinienses», Archivos Leoneses, 65, (1979), pp. 103-110, especialmente pp. 106 y 109.

12 «Nuevas lápidas vadinienses de la provincia de León», Tierras de León, 14, (1971), pp. 67-78.

13 «La nueva estela vadiniense de Pedrosa del Rey (Riaño). Algunos aspectos en relación con el problema de los vadinienses», Tierras de León, 72, (1988), p. 69.

14 «La epigrafía del conventus cluniense. I Las estelas vadinienses», Memorias de Historia Antigua, 6, 1984, p.86. En estudios posteriores la profesora Mํ..$C$. González mantiene la afirmación de un mayor número de inscripciones fechables en s. III (vid. por ejemplo, Los astures y los cántabros vadinienses, Bilbao, 1997, p. 99, y «Observaciones sobre la mención de la origo «intra ciuitatem» en la epigrafía funeraria hispana», en VV.AA. Acta XII Congressus Internationalis Epigraphiae Graecae et Latinae, Barcelona, 2007 , p. 598, trabajo escrito en colaboración con Manuel Ramírez).

${ }^{15}$ Entre otros pueden citarse algunos trabajos incluidos en IGLESIAS, José Manuel y MUÑIZ, J. A. (eds) Regio Cantabrorum, Santander, 1999, tales como los de SANTOS, Juan, "Ciudad y ciudadanos entre los cántabros en época romana», p. 292, e IGLESIAS, José Manuel, «Ciudad y territorio externo: Iuliobriga y Vadinia», p. 302.

${ }^{16}$ LIZ GUIRAL, Jesús, «Epigrafía y Arqueología Vadinienses» en VV.AA., Arqueo-León. Historia de León a través de la arqueología, León, 1996, pp. 83-90, especialmente p. 85.

${ }^{17}$ Esta fue la datación que ofrecimos para esta importante inscripción cuando la dimos a conocer junto con el profesor J. Mangas («Princeps Cantabrorum en una nueva inscripción», Gerión, 15, (1997), p. 327. 
tallados estudios, llevando algunos de los ejemplares hasta el siglo ${ }^{18}$. Esta autora propone una datación general del corpus vadiniense entre los siglos I-III d.C., con mayor presencia en los siglos II y III, atendiendo a criterios basados en los formularios epigráficos ${ }^{19}$. Por nuestra parte, hemos sostenido también una cronología temprana de fines del s. I o inicios del II d.C., en algunos epígrafes, tales como el conocido epitafio de Fuscus Cabedus de Corao (Cangas de Onís) ${ }^{20}$, o en la primera edición científica de un epígrafe hallado en La Uña (Acebedo, [León]) ${ }^{21}$. En fin, incluso la profesora Ma $\mathrm{C}$. González ha modificado su posición sobre la cronología de las inscripciones vadinienses, fechándolas ahora en general entre los siglos I y III d.C. ${ }^{22}$

En conclusión, en el estado actual de la investigación epigráfica podemos afirmar que todavía pervive en cierta manera la idea de una datación más bien tardía, en la línea de la propuesta de Navascués, con una clara mayoría de inscripciones pertenecientes al siglo III. Sin embargo, en los últimos años diversos autores como J. Mangas, I. Sastre, y nosotros mismos venimos defendiendo una datación temprana de algunos ejemplares.

\section{CONSIDERACIONES METODOLÓGICAS}

Una vez revisada la historiografía y situado el estado de la cuestión, antes de entrar de lleno en el intento de fijar su cronología conviene señalar ciertos obstáculos que aumentan la dificultad para establecer una datación, si no precisa, al menos aproximada. Veamos a continuación una síntesis de las principales dificultades.

En términos generales se trata de un conjunto epigráfico casi exclusivamente funerario que ofrece un aspecto general marcadamente rural, muy alejado por tanto de los usos epigráficos comunes en los ambientes urbanos. Esto imposibilita establecer los necesarios paralelos con otras inscripciones bien datadas.

18 «Las inscripciones Vadinienses en el contexto general de la dominación romana del noroeste», Edades. Revista de Historia, 9, (2001), p. 13, nota 8.

${ }^{19}$ Onomástica y relaciones políticas en la epigrafía del Conventus Asturum durante el Alto Imperio, Madrid, 2002, pp. 80-81. Reproduzco aquí su propuesta «S. I: inscripciones sin fórmulas de consagración o con la fórmula $M$ (onumentum) $p$ (osuit) al final. S. II: inscripciones con M(onumentum) p(osuit) al principio, e $h$ (ic) s(itus) e(st) al final, con o sin mención de la relación entre dedicante y difunto (amicus, pater, filius, etc). S. II-s. III: inscripciones con fórmula $D$ (is) M(anibus) M(onumentum) y/o s(it) $t$ (ibi) $t$ (erra,) I(evis). Fin. s.II-s. III inscripciones con formularios tardíos (annorum plus minus, vixit annis; situs hoc sepulchro o con uso de superlativos.»

${ }^{20}$ MARTINO, David, «Lápida funeraria de Fusci Cabedi», Nuestro Museo: Boletín anual del Museo Arqueológico de Asturias, 1, 1997, p. 238.

${ }^{21}$ Idem, «Novedades de epigrafía vadiniense. Dos lapidas reaparecidas y un fragmento inédito», Tierras de León, 115, (2002), p. 152. Vid. infra la citada inscripción.

22 «Epigrafía y sociedad: el ejemplo vadiniense», en SOLÓRZANO Jesús Ángel y GONZÁLEZ, Manuel Ramón (eds), II Encuentro de Historia de Cantabria, vol. 1, Santander, 2005, p. 93. 
Hasta el momento es por completo desconocido el contexto arqueológico asociado a los epígrafes hallados dentro del territorium Vadiniensium ${ }^{23}$. Muchos de ellos son conocidos de antiguo por su reaprovechamiento en todo tipo de edificaciones, unas veces religiosas y las más civiles, de los numerosos caseríos y aldeas de la región montañosa de la que preceden estas inscripciones. Debido a su gran dispersión geográfica y a que, como decimos, no han sido halladas en sus emplazamientos originales, no siempre es fácil precisar la correspondencia entre los epígrafes con los numerosos castros del área, que, por otra parte están en gran medida indocumentados, pues no han sido excavados ni se han realizado estudios amplios de sus materiales ${ }^{24}$.

Los soportes empleados son también muy peculiares, reduciéndose en la mayoría de los casos a piedras sin labrar, o escasamente trabajadas, en las que se aprovechó la parte más lisa para grabar el texto. Se trata de bloques pétreos de tamaño muy diverso que debieron ser elegidos por su dureza y que en su mayoría han sido descritos como cuarcitas, cuarcitas pizarrosas, areniscas o incluso alguna de ellas como caliza cristalina blanca. En todo caso, falta un estudio específico de sus características geológicas ${ }^{25}$. En muchas ocasiones han sido calificados como «cantos rodados» 0 "cantos erosionados fluviales» ${ }^{26}$, usando una terminología no del todo precisa. Por su tipología, estos epígrafes deben incluirse dentro de las estelas funerarias. Algunas de ellas presentan un aspecto que recuerda a las estelas de cabecera semicircular, pero, en todo caso, el análisis de los soportes tampoco ofrece indicios que ayuden a su datación.

En cuanto a la paleografía, hasta el momento carecemos de estudios detallados para este conjunto de inscripciones. Se ha tendido a considerar que unas letras tan toscas e irregulares en su forma y tamaño -incluso dentro de un mismo epitafio- son indicio de una cronología tardía, pero como veremos, no siempre una grafía tosca e irregular remite a épocas tardías y menos aún en zonas rurales y periféricas con marcado predominio de población indígena.

Un numeroso grupo de las inscripciones presentan elementos decorativos muy variados: son frecuentes los caballos, arbolitos, crecientes lunares o torques, alguna hoja de hiedra -nunca con la función de interpunción tan usual en el resto de Hispania- y hasta un caso con una esvástica. Al igual que el resto de las características de este corpus epigráfico, la ornamentación es muy peculiar, particular y casi exclusiva de este populus cántabro. Por todo ello, no disponemos de los paralelos necesarios para utilizar la presencia de uno u otro ornamento como criterio de datación ${ }^{27}$.

\footnotetext{
${ }^{23}$ Precisamente solo conocemos el contexto arqueológico de los dos ejemplares vadinienses hallados fuera del territorio de esta civitas. Se trata de dos epígrafes fragmentados recuperados en la muralla de Monte Cildá (Olleros de Pisuerga, Palencia), cfr. HEp 6, 1996, 701 y 703.

${ }^{24}$ Véase en última instancia LIZ GUIRAL, J., Op. Cit., pp. 86ss, que ofrece una síntesis del escaso conocimiento arqueológico de la zona, señalando la falta de prospecciones, excavaciones y estudios arqueológicos detallados.

${ }^{25}$ Cuestión que ya fue advertida por J.M. Navascués (La estela funeraria... p. 178).

${ }^{26}$ Cfr. GONZÁLEZ, María Cruz, Los astures y cántabros..., p. 98, con bibliografía.
} 
Ninguno de los epígrafes conocidos hasta el momento tiene datación explícita. Existen 6 epitafios en la parte septentrional datados entre los años 316 y 482 por una enigmática «Era consular» habitualmente expresada como aera $\cos 0 \cos ^{28}$. El problema fundamental para la utilización de este sistema de datación como criterio cronológico es que a mi juicio, todavía no se ha resuelto satisfactoriamente cuál es su fecha de inicio. Los autores que han tratado esta cuestión ofrecen propuestas muy variadas, que van desde considerar su comienzo en 206 a.C., así F. Fita y otros, hasta iniciarla con el edicto de latinidad de Vespasiano, según ha sostenido recientemente R.C. Knapp ${ }^{29}$, pasando por hacerla equivalente con la Era Hispánica, que como sabemos comienza en 38 a.C. Esta opción parece que va ganando mayor aceptación últimamente ${ }^{30}$. En todo caso, la presencia de esta Era consular no ha servido para definir criterios cronológicos, más bien al contrario, su utilización ha venido a complicarlo todo aún más.

El análisis de los aspectos internos, tales como el uso de determinadas fórmulas epigráficas, la estructura del epitafio, la onomástica u otros datos también ofrece múltiples inconvenientes dadas las particularidades locales de un ambiente marcadamente rural con un fuerte tono indígena. Bastarán como ejemplos la expresión munimentum/monime(ntum) y otras variantes por monumentum, lebes por levis o possit por posuit, la presencia de la fórmula dibus manibus sin abreviar en pleno s. III, así como la existencia de fórmulas funerarias únicas como $h(O c)$ I(oco) e(st), h(ic) s(itus) t(erra) e(st) o s(itus) h(oc) s(epulcro). Sin embargo, como veremos, solo gracias al análisis de los formularios epigráficos así como de otros elementos del texto epigráfico se consiguen resultados positivos para una definición de la cronología de este conjunto epigráfico.

Por otra parte, la utilización de la onomástica como criterio clave para la datación, en particular como indicio del grado de latinización, no ha resultado eficaz. Hace unos años se propuso un modelo que partía de la premisa de una lineal y progresiva latinización de los antropónimos vadinienses, en el que la combinación de la presencia de nombres indígenas junto a estructuras onomásticas simples con mención a organizaciones suprafamiliares remitían a fechas más tempranas, mientras que las estructuras ciudadanas asociadas a nombres plenamente latinos se correspondían con fechas más recientes ${ }^{31}$. Entre ambos extremos se sitúan distintas fases de evolución entre la onomástica indígena y la plenamente latina, siempre bajo la premisa de una latinización lineal de la antroponimia de los vadinienses en la que se van perdiendo progresivamente los rasgos indígenas. Si

${ }^{27}$ Es imposible llegar a conclusiones similares a las del profesor J. A. Abásolo, quién al hilo del estudio ornamental de dos estelas funerarias de militares de la cuenca del Duero puede concluir que ciertos elementos decorativos que se repiten en muchas estelas funerarias y que tradicionalmente se venían considerando tardíos existían ya en el siglo I d.C. (cfr. «Acerca de la cronología de algunos monumentos funerarios. Las estelas de Contreras y Tardemézar», BSAA, 56, (1990), 297-306).

${ }^{28}$ Repertorio actualizado en ABASCAL, Juan Manuel, «La Era consular hispana y el final de la práctica epigráfica pagana», Lucentum, XIX-XX, (2000-2001), pp. 269-292.

29 «Cantabria and the Era consularis», Epigraphica, 48, (1986), p. 132.

${ }^{30}$ Véase en última instancia el trabajo de J.M. Abascal (op. cit., p. 271).

${ }^{31}$ GONZÁLEZ, María Cruz, y SANTOS, Juan, «La epigrafía del conventus...», pp. 88ss. 
bien es obvio que en los momentos iniciales de la dominación romana deben predominar los nombres cántabros y con el tiempo se van introduciendo los latinos, estamos de acuerdo con la crítica a la que fue sometido este modelo por I. Sastre $^{32}$. Sin entrar en detalles, baste con mostrar algunos ejemplos ilustrativos que muestran lo inadecuado de considerar que los antropónimos indígenas remiten siempre a épocas tempranas y los latinos a fechas tardías. Así por ejemplo, una estela de Liegos, claramente de pleno siglo III, es dedicada por Aliomus, o en $\mathrm{Pe}-$ drosa del Rey, del mismo siglo, el difunto es Boderus Sdubleginus.

Para finalizar estas consideraciones metodológicas, conviene dedicar unas palabras a definir la muestra de estudio, es decir establecer el corpus para el que vamos justificar la cronología. Según los datos disponibles el corpus de epigrafía vadiniense se compone de un total de 74 ejemplares ${ }^{33}$, casi todos ellos son funerarios, salvo dos votivos ${ }^{34}$. En este trabajo nos limitaremos a los 69 epitafios hallados dentro del amplio territorium de la civitas de los vadinienses. Este territorio engloba una zona muy homogénea y bien delimitada por accidentes naturales que a grandes rasgos se extendía por la zona montañosa de la cordillera Cantábrica regada por el curso alto del río Esla y sus afluentes Porma y Cea en la provincia de León y por el curso alto del río Sella y sus afluentes Ponga y Güeña en Asturias, abarcando un espacio de unos 2300 km² $^{2}$ aproximadamente ${ }^{35}$. Los epígrafes se agrupan en dos focos claramente diferenciados: el grupo meridional o cismontano -parafraseando, si se me permite, a Plinio-, en la actual provincia de León, mucho más numeroso, con 52 ejemplares, y el septentrional o transmontano, en Asturias, con 16. Para todos los epígrafes ofreceremos una propuesta cronológica, a excepción de tres que a la vista de su estado fragmentario o por la dificultad de su lectura solo podemos afirmar que pertenecen a época altoimperial ${ }^{36}$.

\section{INSCRIPCIONES DEL SIGLO I D. C.}

Sabemos por las fuentes literarias que los cántabros habían entrado en contacto con los romanos por lo menos en el siglo I a.C., pero no fueron definitivamente so-

32 Onomástica y relaciones políticas... pp. 80-81.

${ }^{33}$ Incluyendo los dos hallados en Monte Cildá.

${ }^{34}$ Uno de Crémenes: I(ovi) O(ptimo) M(aximo) M(arcus) / lan(uarius) pro s(alute) / F(lavi) Muci Calist/iani v(otum) lib(ens) s(olvit) (HEpOL 18440) y el otro de Boñar (León): Fonti sacr[um] / Brocci l(ibertus) Vipst[anus] /Alexis aquilegus / v(otum) s(olvit) I(ibens) m(erito) // Genio [- - ] (HEpOL 8520).

${ }^{35}$ En otro lugar hemos justificado la delimitación del territorium Vadiniensium, cfr., MARTINO, David, «Propuesta de delimitación del territorio de la civitas de los vadinienses», en CRESPO, Santos, y ALONSO, Ángeles (coords), Scripta antiqua in honorem Ángel Montenegro Duque et José María Blázquez Martínez, Valladolid, 2002, pp. 621-631. Excluimos por tanto algunos ejemplares que si en ocasiones han sido incluidos por su semejanza tipológica, se encuentran claramente fuera de los límites de esta civitas: el epígrafe de Barrillos de Curueño (HEpOL 12030), el de Velilla de Guardo (HEpOL 12652), uno de procedencia desconocida (HEpOL 19291) y el de Cármenes, visto ya supra n. 7. Dejamos fuera también el epitafio de un veterano hallado en Crémenes que a todas luces parece un militar forastero y por lo mismo su epígrafe se aparta de los usos comunes entre los vadinienses: $M(\operatorname{arco})$ lulio Cr(escenti) / vet(erano) leg(ionis) XX/h(ic) [s(itus?) e(st?)] (HEpOL 19261).

${ }^{36}$ Se trata de inscripciones de la parte leonesa, una de Aleje (HEpOL 6583: [- - -]C[- - - ] / amico su[o / B]alaeso Fr[o]/ntoni an(norum) [- - - / h(oc) I(oco) e(st), otra de Horcadas (MARTINO, David, «Nove- 
metidos, si atendemos a la versión oficial, hasta la época de Augusto como consecuencia de las célebres Guerras Cántabras (29-16 a.C.) ${ }^{37}$. Podemos, por tanto establecer una fecha post quem y esperar, por tanto, que el hábito epigráfico se iniciase como muy pronto ya a fines del siglo I a.C. o más seguramente en los inicios del siglo I d.C., situación que no desentona con otras zonas del norte peninsular ${ }^{38}$.

Sin lugar a dudas, el epígrafe más antiguo del corpus vadiniense recuperado hasta el momento es el epitafio del princeps Cantabrorum ${ }^{39}$. La sencillez general del texto, la falta de cualquier decoración, la ausencia de fórmulas de consagración, la mención del difunto en nominativo, la fórmula final $h$ (ic) s(itus) e(st), así como la estructura onomástica sencilla y la propia antroponimia indígena, remiten de forma inequívoca al siglo I d.C., tal como sostuvimos junto con el profesor Mangas en la editio princeps de este epígrafe. Ahora bien, últimamente la profesora $\mathrm{M}^{\mathrm{a}} \mathrm{C}$. Gonzalez ha propuesto que debe datarse probablemente en época fla$v^{4}{ }^{40}$. No vemos razones para llevar este epígrafe al último tercio del siglo I, más bien al contrario, el uso del nominativo en vez del genitivo/dativo así como el resto de los elementos inducen a pensar mejor en una cronología más temprana. Además, no sería extraño que Amparamus, el padre de Doviderus, hubiera sido también un princeps, quizás el primero o segundo en el tiempo. En definitiva, proponemos ahora una datación no posterior a mediados del siglo I d.C., para este epígrafe.

Sostener que otros ejemplares se fechan en el siglo primero resulta más difícil, en nuestra opinión no serían más de unos pocos casos, todos ellos procedentes de la parte cismontana del territorium vadiniense. Entre estos, incluimos un epitafio de Crémenes ${ }^{41}$ en el que el difunto aparece en nominativo y el texto presenta una estructura parecida a la del princeps. Quizás sea también de este siglo una inscripción en genitivo muy desgastada hallada en Utrero ${ }^{42}$. En cuanto a sendos epígrafes de Reyero ${ }^{43}$ y Crémenes ${ }^{44}$ que presentan un texto sencillo sin fórmulas de

dades de epigrafía...», pp. 153-156=HEp 12, 2002, 318: [- - - - - / - - - Bod- Doid?]erus / [Loan?]cian/[us] $\cdot s($ uo?) $\cdot$ po(suit, -suerunt) m(onumentum) / A Ab(ili-?) · fil(i-) / + · an(norum) XI), y una de Verdiago (HEpOL 17197: M(onumentum) / [- - -] Quirina Qui[ntillus(?) / - - - I]eg(ionis) IX His(panae) a[n(norum) - - - / - - P]isonis(?) f(ilius) p(osuit) [- - -]).

${ }^{37}$ Se tienen noticias de revueltas de los astures todavía en época de Nerón (cfr. CIL XI, 395), lo que no descarta una situación similar entre los Cantabri.

${ }^{38}$ En este sentido, se ha sostenido que el famoso Pacto de hospitalidad de Herrera de Pisuerga fechado en 14 d.C. pudiera ser el más antiguo documento epigráfico vinculado con los vadinienses, en razón de la antroponimia del firmante: Amparamus Nemaioq[um] / [Cu]saburensis.

${ }^{39}$ Dovider/us • Ampa/rami • f(ilius) • pr/inceps $\bullet$ Ca/ntabroru/m • h(ic) • s(itus) • e(st) • De/obrigi • f(ilii -ecerunt?) • p(osuerunt) •/m(onumentum) •(MANGAS, Julio y MARTINO, David, Op. Cit. pp. 321-323 $=H E p O L$ 7456)

40 «Epigrafía y sociedad: el ejemplo vadiniense», en Actas del I/ Encuentro Historia de Cantabria, (2005), p. 98 .

${ }_{41}$ lunius Aravu[m] / Abili f(ilius) Vad(iniensis) an(norum) XX[.] / h(ic) s(itus) e(st) / nepotes sui posierun[t!] (HEpOL 19272). Puesto que la piedra está partida y faltan letras en el lado derecho, no es descartable que al final de la última línea se haya perdido m(onumentum).

42 Cilli Vir/onigi / Arenni f(ilii) an(norum) / - - - (HEpOL 12044).

${ }^{43}$ Meduge/no Valenti / Magilonis / f(ilio) an(norum) XL (HEpOL 19285)

${ }_{44}$ (Pentio [Fe] / oto Do[vid] /eri f(ilio) V[ad(inieron))] / an(norum) XX / h(ic) s(itus) e(st) / amici / ob m(erita) (HEpOL 19274). 
consagración y con el difunto en dativo, en ocasiones han sido datados en el siglo $\mathrm{I}^{45}$, pero consideramos que habría que llevarlos como mínimo a fines del siglo I, si no es que pertenecen ya a pleno siglo II, en atención a que el uso del dativo es más tardío que el del nominativo o genitivo y como es conocido se generaliza en el siglo II. De igual modo hemos datado a fines del s. I o inicios del s. II d.C. una estela dada a conocer no hace mucho procedente de La Uña (Acebedo) ${ }^{46}$. A estas inscripciones cabría añadir, quizás, otra de las procedentes de Gémenes ${ }^{47}$.

Como acabamos de ver, hasta el momento son pocos los epígrafes adscritos al siglo I, aparte del ejemplar del princeps Cantabrorum, solo podemos proponer entre 2 y 7 si incluimos los probables. Sin embargo, el análisis detallado del corpus vadiniense permite aislar un grupo reducido pero significativo de inscripciones hasta el momento halladas solo en la zona leonesa que como veremos bien podrían ampliar la nómina de ejemplares del siglo I. Estas inscripciones comparten las siguientes características: son epitafios muy sencillos encabezados por munimentum o munim(entum) (sic), con el difunto consignado en genitivo y la indicación de origo sin abreviar (Vadiniensis). El difunto presenta una estructura onomástica sencilla (cognomen indígena + filiación, y sólo en algunos casos dos cognomina). Además, dichas estelas carecen de decoración si bien en algunas de ellas el campo epigráfico ha sido delimitado por líneas que también se han utilizado para marcar los renglones. Paradigma de este grupo es una estela de Liegos (Acebedo) ${ }^{48}$ de la que presentamos un dibujo (Figura 1), así como otras tres halladas en Puente Almuhey (Valdermeda) ${ }^{49}$, Pedrosa del Rey ${ }^{50}$ y Velilla de Valdoré (Crémenes) ${ }^{51}$, que dadas las semejanzas entre ellas bien pudieran pertenecer a la misma officina epigráfica. A este grupo cabría añadir otra muy parecida que presentan alguna variante procedente de Crémenes ${ }^{52}$. p. 168)

${ }^{45} \mathrm{Al}$ siglo I ha sido adscrito el ejemplar de Reyero por I. Sastre (Onomástica y relaciones políticas...,

${ }^{46}$ Aliomo / Victori / Numisi(i) / f(ilio) Vadi(niensi) / an(norum) XXX / h(ic) s(itus) (MARTINO, David, «Novedades de epigrafía..., p. $152=$ HEPOL 17904).

${ }^{47}$ Amparamo / Brigetino (HEpOL 19268).

48 Munimentum / Caelionis / Amparami f(ili) / Vadinie(n)sis (HEpOL 19278) Mantenemos su adscripción al grupo de Liegos, tal como afirma F. Diego (Inscripciones romanas de la provincia de León, León, 1986, no 274) aunque Gómez Moreno (Catálogo monumental... p. 46) señaló que desconocía su procedencia.

${ }^{49}$ Munime(ntum) / [D]oviteri / [.]etoni / ++Iti f(ilii) / Vadiniens(is) / an(norum) [- - -] (MARTINO, David, «Noticia sobre lápida vadiniense en Puente Almuhey (León)», Tierras de León, 99 (1995), pp 57-62=HEpOL16192).

${ }^{50}$ Munim(entum) / Tedi Vicani / Vadiniensis / Doiteri f(ilii) / an(n)orum / XXX (HEpOL 19281) Actualmente desaparecida, su texto fue dado a conocer por Gómez Moreno (Catalogo monumental... p. 43) sin aportar fotografía. En la segunda línea se mantiene la duda en la lectura de Vicani, entendido como habitante de un vicus o como antropónimo, (cfr. GONZÁLEZ, María Cruz, Los astures y cántabros... p. 96 n. 270).

51 . - - - - loi Vadinien(si) / OB Boveci fili(i) / an(norum) XXV (HEpOL 12042). Aunque se ha perdido gran parte de la estela, por lo conservado no hay duda de la semejanza con las anteriores.

${ }_{52}$ Monime(ntum) / Necali Ca/laca Abru/naeni f(ilii) Va[d(iniensis)] / Daeceius / posuit o(b) m(erita) /ne(poti?) s(ui?) TRES / an(norum) XXX (HEpOL 6717). 


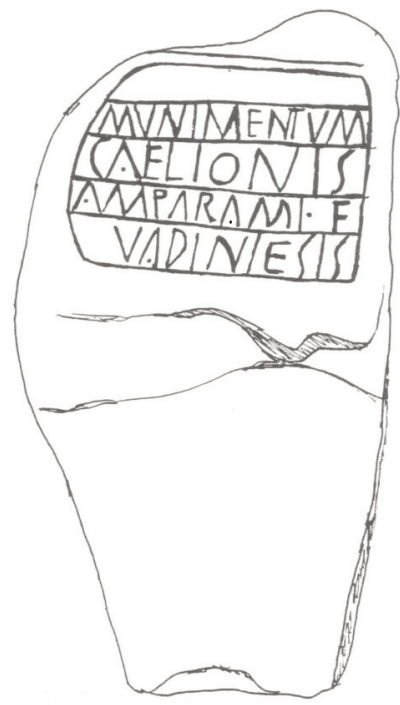

Fig. 1. Estela de Caelio (Liegos) (HEpOL 19278) (Dibujo del autor)

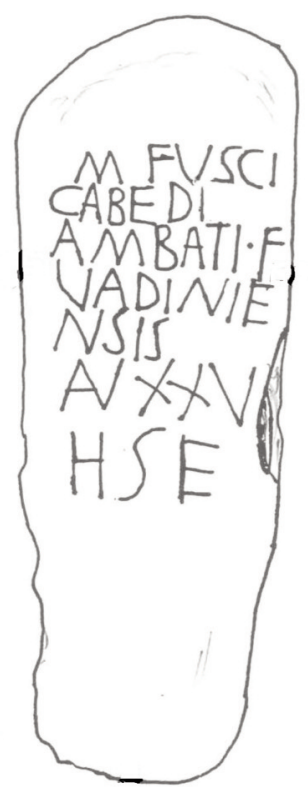

Fig. 2. Estela de Fuscus Cabedus (Corao) (HEpOL 8535) (Dibujo del autor) 
Nos parece que la expresión de monumentum (con la peculiar variante munimentum) y Vadiniensis sin abreviar, la sencillez general del epitafio, la expresión del difunto en genitivo así como el aspecto general de estos epígrafes son claros indicativos de una datación temprana. Más difícil es precisar la fecha para este conjunto, no obstante, sabemos que en general la mención del difunto en genitivo suele ser ligeramente posterior al uso en nominativo y en todo caso anterior al dativo. $\mathrm{Si}$ aceptamos los márgenes cronológicos generales para fechar las inscripciones en genitivo y por lo mismo no consideramos que éste sea un uso epigráfico particular de los vadinienses, consideramos que estos epígrafes deben datarse en el siglo I d.C., quizás en el último tercio. Proponemos por tanto una datación en época flavia.

En conclusión, si hasta el momento la literatura científica consideraba como una excepción los epígrafes fechados en el siglo I, en el mejor de los casos no más de 6 ejemplares ${ }^{53}$, con nuestra nueva propuesta cronológica el recuento se aumenta hasta 8 seguros, 12 si incluimos los de fines del siglo I-inicios del II. Siguen siendo una minoría y hasta el momento solo podemos asegurar la existencia de inscripciones de este siglo en la parte cismontana del territorium vadiniense.

\section{INSCRIPCIONES DEL SIGLO II D. C.}

Desde el punto de vista formal, el conjunto más numeroso de epígrafes vadinienses está formado por estelas que presentan un epitafio encabezado por $m$ (onumentum) en una primera línea, al que sigue ya en la segunda línea el nombre del difunto en dativo/genitivo + origo abreviada en el forma $\mathrm{Vad}+h$ (ic) s(itus) $e(s t)+$ dedicante $+p$ (osuit). Se trata de un grupo muy homogéneo formado por 27 ejemplares, incluyendo también aquellos que presentan alguna variante menor. Estos ejemplares se distribuyen tanto por la parte cismontana como por la transmontana y suponen en torno al $40 \%$ del corpus.

Proponer unos márgenes cronológicos para este grupo presenta serias dificultades. Ninguno de los epígrafes contiene elementos internos o externos que permita fijar una datación segura. No obstante, la presencia de varios elementos orientan hacia considerarlo un grupo que debe datarse con posterioridad al siglo I y en todo caso antes del siglo III. A saber, la mención del difunto en dativo remite a fechas posteriores a fines del siglo I y tanto la ausencia de los nombres abreviados en tres letras como la falta de fórmulas de consagración tales como $D$ (is) m(anibus) o $D$ (is) m(anibus) m(onumentum) p(ositum) indican una datación en todo caso anterior al siglo III. Consideramos, por tanto, que la conjunción del encabezamiento $M$ (onumentum) ya abreviado más el difunto en dativo y la breve fórmula de deposición $h$ (ic) s(itus) e(st) orientan a fechar estos documentos durante el siglo II d.C. Conviene señalar que los primeros ejemplos de epígrafes con ornamentación típica vadiniense (arbolitos, caballos, hojas de hiedra) que son muy frecuentes en las inscripciones más recientes comienzan a aparecer en este conjunto.

${ }^{53}$ A esta cifra asciende el recuento efectuado por I. Sastre (Onomástica y relaciones políticas...pp. 167-168. 


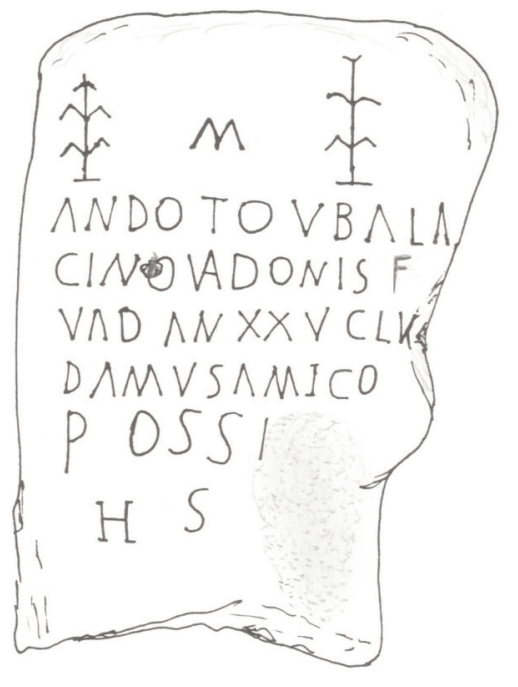

Fig. 3. Estela de Andotus (Liegos) (HEpOL 19277) (Dibujo del autor)

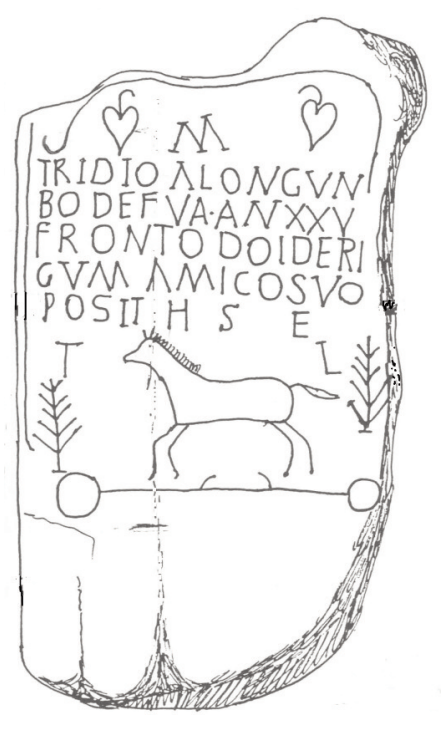

Fig. 4. Estela de Tridius (Remolina) (HEPOL 6585) (Dibujo del autor) 
Si nos centramos en el grupo de epígrafes que presentan al difunto en genitivo y tenemos en cuenta que la expresión en genitivo usualmente corresponde a fechas más tempranas que en dativo, tal como hemos dicho supra, podemos sugerir para estos una fecha en torno a inicios del siglo II d.C, o incluso a fines del I. La estela de Fuscus Cabedus de Corao (Cangas de Onís) de la que adjuntamos dibujo es un buen ejemplo ${ }^{54}$ (fig. 2). Proponemos la misma datación para otro epígrafe de Corao ${ }^{55}$, así como para el hallado en el Puerto de San Isidro (León) ${ }^{56}$ y los cuatro procedentes del municipio de Crémenes: de las aldeas de Verdiago ${ }^{57}$, Ale$\mathrm{je}^{58}$, Valdoré $^{59}$ y Velilla de Valdoré ${ }^{60}$.

En cuanto a los epígrafes con el difunto en dativo, admitiendo que son posteriores, los datamos en pleno siglo II d.C. La relación de estos 20 epígrafes es la siguiente: un ejemplar procedente de Villaverde (Cangas de Onís) ${ }^{61}$, los dos ejemplares hallados en Armada (Vegamián) ${ }^{62}$, uno de Fuentes de Peña Corada (Cistierna) ${ }^{63}$, otro de Santa Olaja de la Varga (Cistierna) ${ }^{64}$, uno de Sabero ${ }^{65}$, dos de Liegos (Acebedo) ${ }^{66}$ (fig. 3), uno en Valverde de la Sierra (Boca de Huérgano) ${ }^{67}$,

${ }^{54}$ M(onumentum) Fusci / Cabedi / Ambati f(ilii) / Vadinie/nsis / an(norum) XXV / h(ic) s(itus) e(st) (HEpOL 8535). Nótese que la origo no se inscribe abreviada, lo que precisamente podría reforzar la idea de una fecha temprana.

${ }_{55}$ M(onumentum) / Penti Flavi Vic[to]/ris f(ilii) Vad(iniensis) an(norum) XXX / pater ei pro me[r](ita) / $\operatorname{pos}\{s\}(u)$ it (HEPOL 8538)

${ }^{56}$ M(onumentum) / Andoti Fl/avi Areni f(ilii) / an(norum) LX / h(ic) s(itus) e(st) (CIL II 2696=5675, HEPOL 8522).

${ }^{57}$ M(onumentum) / Turrom[i] / Va(diniensis) Com(i) f(ilii) / an(norum) XXV / Pude(n)s fr(atri) / pos(uit) / h(ic) s(itus) e(st) (HEpOL 14889).

${ }_{58}$ M(onumentum) / Penti(i) / Balaesi f(ilii) / Vadini(ensis) / an(norum) XXX / Viamus / p(osuit) Alisste/giani (filius?) h(ic) / s(itus) e(st) (HEpOL 12870)

${ }^{59}$ M(onumentum) / Munigaligi / Arani Bouti f(ilii) / Vad(iniensis) an(norum) XXV / h(ic) s(itus) h(est?) (HEPOL 12037).

${ }^{60}$ Manili(i) Ar/av(u)m Elan/i f(ilii) Va(diniensis) an(norum) XXX / Cadus av(u)n/culo suo / p(osuit) $h$ (ic) $s$ (itus) e(st) (HEpOL 12036), dado que la piedra se encuentra mutilada en la parte superior, no descartamos que se haya perdido una primera línea con $M$ (onumentum).

${ }^{61}$ M(onumentum) [- - -] / Cassio / Corovescum / [- - -]ivi fil(io) Vadi/niensi / [an(norum)]IX(?) V/[- - ] fil(io) suo [p(osuit)] ( HEPOL 8534).

${ }_{62}$ M(onumentum) / Ablon/nio Tauri/no Doid/eri f(ilio) Va/d(iniensi) anno/rum XXX / h(ic) s(itus) e(st) / Placidus / av(u)nculis / po(suit) (HEpOL 12028) y [M(onumentum)] / Virono Taur[i/n]o Doideri F(ilio) / Vad(iniensi) annoru/m XL H(ic) s(itus) e(st) / Placidus Av(u)nculis pos(uit) (HEpOL 12040) Por la similitud con la anterior y puesto que se está partida en la parte superior, ya Hübner restituyó m(onumentum?) en la primera línea.

${ }_{63}$ M(onumentum) / Amba[to] / Placi[do Am]/bati [f(ilio) an(norum)] XXX [- - -]/us [- - - ] pos(uit) / h(ic) [s(itus) e(st)] (HEpOL 6584), aunque la estela está muy desgastada, no cabe duda de que por su composición corresponde a este grupo.

${ }^{64}$ M(onumentum) / [Pe]ntovio Ela/[es]o militi a(lae?) / [II] Vad(iniensi) an(norum) XXV / [Ela]nus Arga / [am]ico p(osuit) h(ic) s(itus) e(st) (HEpOL 6718). Lo extraordinario de la lectura en línea 3 ya fue advertido por J. Mangas en HEp 8, $1998,327$.

65 Mon(umentum) / L(ucio) Antonio / Aquili f(ilio) / Vad(iniensi) an(norum) / XX Lepid/us nep(oti) s/uo p(osuit) (HEpOL 19288). En la parte inferior se ha grabado un caballo.

${ }^{66} \mathrm{M}$ (onumentum) / Andoto Ubala/cino Vadonis f(ilio) / Vad(iniensi) an(norum) XXV Clu/damus amico / $\operatorname{pos}\{s\}(u) i[t] / h($ ic) s(itus) [e(st)] (HEpOL 19277) y M(onumentum) Neconi / Boddegun Loan/cinis fili(o) Va(diniensi) ann(orum) / XXI Aurelius Pro(culus) / pos(uit) am(ico) suo / mun\{n\}iment(um!) (HEpOL 12038).

${ }^{67} \mathrm{M}$ (onumentum) / Caesaron[i / I]ulibagi / [fi]lius an(n)o/rum XXXX / [.]utuda Am(m)ia / [pa]tri posuit / [V]adinie(n)sis / [h(ic)] s(itus)] e(st) (HEpOL 12032), nótese la falta de concordancia entre el nombre del difunto y la origo). 
cuatro de Riaño ${ }^{68}$ y los cinco procedentes del municipio de Crémenes (tres de la localidad homónima ${ }^{69}$, uno de Lois $^{70}$ y otro de Remolina ${ }^{71}$ ) (fig. 4). A estos hay que añadir los recientes descubrimientos de Riaño ${ }^{72}$ y en el valle de Valdoré (Crémenes) ${ }^{73}$.

Como cabe esperar, en el corpus epigráfico vadiniense también encontramos un grupo significativo de textos funerarios que se inician con la fórmula de consagración $d$ (is) $m$ (anibus). Aunque se trata del grupo más heterogéneo de los vistos hasta ahora en cuanto a la estructura del epitafio, suelen presentar al difunto en dativo y se acompaña de profusa decoración. Es bien conocido que la presencia de la fórmula de consagración $d$ (is) m(anibus) $s$ (acrum) es utilizada como argumento para fijar los márgenes cronológicos de las inscripciones, pues comienza a generalizarse en las provincias hispanas a partir de inicios del siglo II y se mantiene presente hasta bien entrada la tercera centuria ${ }^{74}$. En un principio no es descartable que los textos vadinienses que se inician con esta fórmula fueran contemporáneos a los que están encabezados por M(onumentum), sin embargo, existen muchos que presentan indicios para considerar sin duda una datación en el siglo III. Por tanto, si como decimos los documentos con la fórmula $d$ (is) $m$ (anibus) pueden adscribirse tanto al siglo II como al III, pensamos que aquellos que no presenten otros elementos para su datación en la tercera centuria deben ser del siglo II, posición que se refuerza porque muchos de ellos emplean la formula breve $h$ (ic) $s$ (itus) e(st). Además, se podría entender que los epitafios encabezados por m(onumentum) corresponden a un uso epigráfico más antiguo que los encabezados por $d$ (is) m(anibus) que progresivamente se fue imponiendo a la vez que se fue

${ }^{68}$ M(onumentum) / Elanio Veliagu(m) / filius Paterni / an(norum) XXX Trida/llus p(osuit) amico suo / s(itus) h(oc) s(epulchro) (HEpOL 12883); M(onumentum / [Bo]d[ero] Pent[i]/ocum Tridi fil(io) / Vad(iniensi) anno(rum) XXX / Arenus Andoti / am(ico) sv(o) po(suit) (HEpOL 6580); [T]uranto [- - - / Pe]ntiocum [- - / - - -]vivi f(ilio) ann(orum) [- - -]/Sempr[onius / - - -] p(osuit) fratri s(uo) (HEpOL, 12041, muy desgastada y fragmentada en el costado izquierdo, es muy posible $M$ (onumentum) en una primera línea) M(onumentum) / [- - ]us Cadaric(um?) / [Ara]vi filius / [- - - an(n)oru(m) XX[- - - / - Ar]aus f(ilio) pos(u)i[t / h(ic)] s(itus) [e(st)] (HEpOL 19287, muy desgastada, es un caso excepcional al presentar al difunto en Nominativo).

${ }^{69}$ M(onumentum) / Segi[- - -] / Mar[- - - / Vad(iniensi) an(norum) [- - -] / h(ic) s(itus) e(st) D[oci]/us p(atri) pos(uit) (HEpOL 19275); M(omumentum) / [- - -]o Flacco / Flacci f(ilio) Vad(iniensi) an(norum) / $X X X$ Aurelius patri / f(aciendum) $c$ (uravit) $h$ (ic) s(itus) e(st) (HEpOL 19271, sustituye posuit por faciendum curavit) y M(onumentum) Bovec[io] Tusc/o Quesadioc<i f(ilio)=H>] / Vad[iniesis an(norum)] / XXI MLLFAT Dacia / [P]arnua m(ater) p(osuit) (HEpOL 19269).

${ }_{70} \mathrm{M}$ (onumentum) / Ambato Param/onis f(ilio) Vad(iniensi) an(norum) / XXX Origenus / cognato suo / p(osuit) h(ic) s(itus) e(st) (HEpOL 19280).

${ }^{71} \mathrm{M}$ (onumentum) / Tridio Alongun / Bode f(ilio) Va(diniensi) an(norum) XXV / Fronto Doideri/gum amico suo / pos(u)it h(ic) s(itus) e(st) / (sit tibi) t(erra) I(evis) (HEpOL 6585).

${ }^{72} \mathrm{M}$ (onumentum)/ Cado Cor(nelii)[f(ilio)]/ R[e]bon/Vad(iniensis) an(norum)/XXV Alio/mus am[i]/co suo/ $h$ (ic) s(itus) e(st) (GONZÁLEZ MIGUEL, Evelio, y GONZÁLEZ MANUEL, Pedro Luis, "Nueva lápida vadiniense. La lápida vadiniense de Cado Cornelio en Riaño», Revista Comarcal Montaña de Riaño, 39, (2011) disponible también on line: http://www.revistacomarcal.es/Revista_39/nueva-lapida-vadiniense.html.

${ }^{73}$ Dada a conocer en Diario de León (www.diariodeleón.es, a fecha 5-12-2011), en vista de la fotografía es indudable que presenta la estructura $M$ (onumentum) + dativo + dedicante + $p($ osuit) $+H S E$, si bien se ha perdido la primera línea por fractura de la pieza.

${ }^{74}$ ALFÓLDY, Geza, Die Römisches Inschriften von Tarraco, Berlín, 1975, p. 477. 
abandonando el anterior. De hecho, se conserva un epígrafe que podría interpretarse a modo de transición pues en él coexisten los dos formularios: se trata del único ejemplar hallado hasta el momento en Valmartino (Cistierna) ${ }^{75}$.

En fin, por todo lo dicho, lanzamos la hipótesis de considerar de la segunda mitad del siglo II a aquellos epígrafes que comienzan con la fórmula $d$ (is) $m$ (anibus) y no presentan otros elementos que los daten en la siguiente centuria. Hasta el momento, incluyendo la que acabamos de ver de Valmartino, las inscripciones de este conjunto proceden todas ellas de la parte cismontana: tres procedentes del término de Crémenes (uno de Remolina ${ }^{76}$, uno de Velilla de Valdoré ${ }^{77}$ y otro de Verdia$\left.\mathrm{go}^{78}\right)$, el único hallado en Sorriba (Cistierna) ${ }^{79}$, otro de Villapadierna (Cubillas de Rueda) (fig. 5) ${ }^{80}$, uno de Carande (Riaño) ${ }^{81}$ y otro, muy probable por su estado fragmentario, de Vega de Monasterio (Cubillas de Rueda) ${ }^{82}$. A estas, cabría añadir una más procedente de Argovejo (Crémenes) ${ }^{83}$, pieza que por la presencia del superlativo pientissimus podría datarse en el siglo III -tal como se ha venido haciendo comúnmente para los epígrafes vadinienses que presentan epítetos en superlativo, sin embargo, este indicio por si solo no es concluyente pues conocemos ejemplos de su uso ya en el siglo $\|^{84}$. Por otra parte, el aspecto general de esta estela en cuanto a texto y decoración invita mejor a colocarla junto a las del siglo II.

En resumen, para el siglo II proponemos un total de 36 epígrafes: todos aquellos que están encabezados únicamente por $M$ (onumentum), cuyo recuento asciende hasta 27, a los que añadimos algunos de los que emplean la fórmula $d$ (is) m(anibus) y datamos ya en la segunda mitad de la centuria, un total de 9 ejemplares. Esto supone que más de la mitad de los epígrafes del corpus corresponden al siglo II, distribuyéndose tanto por la zona norte como por la sur.

${ }^{75} \mathrm{M}$ (onumentum) D(is) ma(nibus) / Dovide/ara f(ilio) p(osuit) / Negalo / Vironigo/ru(m) an(norum) XXV (HEPOL 12034) Hübner lo dató por paleografía en el siglo I, véase supra n. 3.

${ }^{76} \mathrm{D}$ (is) M(anibus) / Vadone Bi/racidegino / Anemidi f(ilio) Va(diniensi) / an(norum) XXX Lugua Ca/ddecun am/ico suo pos(u)it / h(ic) s(itus) e(st) (HEpOL 19284)

$77 D$ (is) M(anibus) / Doidero / Arcaun Bo/deri f(ilio) Vad(iniensi) / an(norum) XXX Turanto / Bodeccun / amico suo / posuit / h(ic) s(itus) e(st) (HEpOL 6896).

${ }^{78}$ [ D(is)] M(anibus) / [Pen]tio Vir/[oni]gun Ca/[di f(ilio)] an(norum) XL / [- - -JV / [- - -]O / [h(ic)] s(itus) e(st) (HEpOL 12043)

${ }^{79} D$ (is) M(anibus) / Bodero / Bodives(cum) / Doideri f(ilio) / a(nnorum) XXV / filio suo / m(ater) p(osuit) h(ic) s(itus) / est (HEpOL 12031).

${ }_{80} D$ (is) M(anibus) / Cangilus / Virono / av(u)nculo / suo Segis/ami f(ilio) Va(diniensi) / an(norum) XXXV / h(ic) s(itus) e(st) (HEpOL 12033).

${ }_{81} D$ (is) M(anibus) / Pentovi(u)s / Petroniu/s ami(co) su(o) / Bodero M/a(terno) Bod(di) fi(lio) Va(diniensi) / an(norum) XX h(ic) / s(itus) e(st) D (HEpOL 19266)

${ }^{82} D$ (is) Ma(nibus) / [A]renus / [Al]iomigu $(m) /$ Manilio / [..]dolo / [..]atri suo / [.]A[-c.3-] III O/[- - -] ++ (MARTINO, David, «Novedades de epigrafía...», pp. 144-149 =HEpOL 19290. Mantenemos ahora la datación que propusimos en su día).

${ }^{83} D$ (is) M(anibus) / [T]urenno / [B]oddegun / [B]oddi f(ilio) Vad(iniensi) an(norum) / XXX pos(u)it / [D]oiderus pa/tri suo pien/tissumo / s(itus) h(oc) s(epulchro) (HEpOL 19265)

${ }^{84}$ Cfr. HEPOL 18089, procedente de Barcino, datación de inicios del siglo II. 


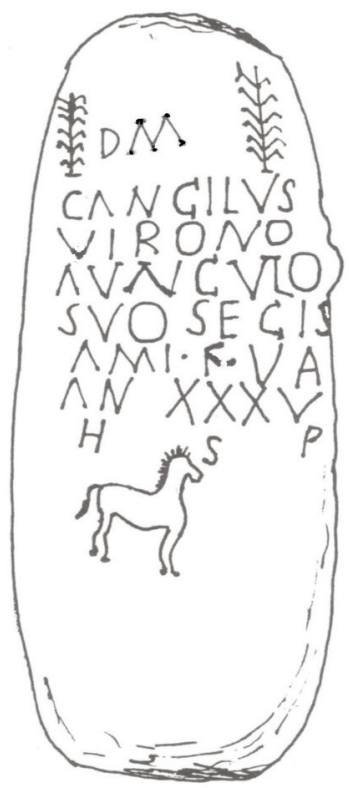

Fig. 5. Estela de Vironus (Villapadierna) (HEpOL 12033) (Dibujo del autor)

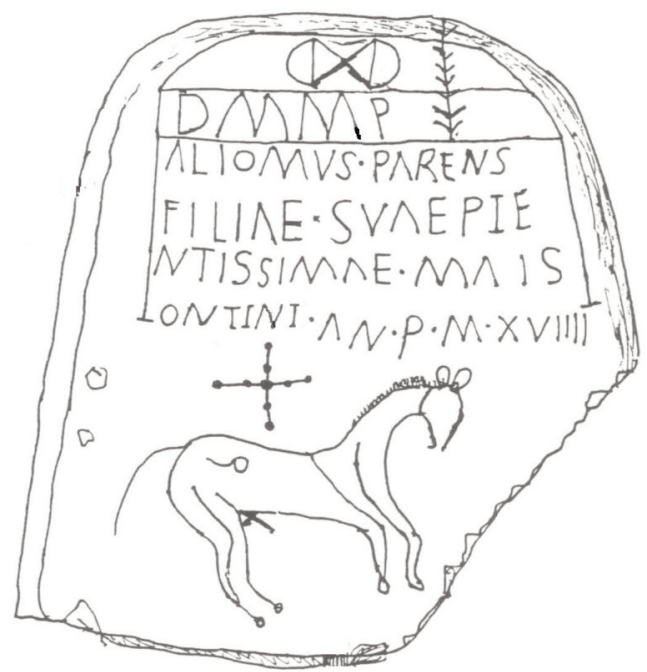

Fig. 6. Estela de Maisontina (Liegos) (HEpOL 12025) (Dibujo del autor) 


\section{INSCRIPCIONES DEL SIGLO III D. C.}

En el estado actual de la documentación epigráfica relativa al conjunto vadiniense, aquellos documentos pertenecientes al siglo III son los más fáciles de fechar, gracias a que contamos con sendos epígrafes bien datados por los cónsules epónimos que aunque no pertenecen al conjunto vadiniense, proceden de áreas limítrofes y son muy semejantes en la estructura de los epitafios y en los formularios epigráficos, y por tanto, nos parecen adecuados para establecer paralelos cronológicos. Los epígrafes en cuestión son: una estela hallada en Cofiño (Parres, Asturias) en el límite mismo del territorium Vadiniensium con sus vecinos los Orgenomesci, datada en 268 d.C. ${ }^{85}$; y un epígrafe procedente de Monte Cildá (Olleros de Pisuerga, Palencia) cuya fecha es 238 d.C. ${ }^{86}$, también de un ámbito geográfico próximo a los vadinienses ${ }^{87}$. Estos documentos confirman la permanencia a mediados del siglo III de las fórmulas $d$ (is) m(anibus) y la peculiar monumentum positum dibus manibus, así como la costumbre de abreviar los antropónimos en tres letras. También demuestran la pervivencia de la alusión a la origo incluso después de la concesión universal de ciudadanía por Caracalla.

Por otro lado, entre los investigadores de la epigrafía vadiniense ha sido frecuente la utilización de otros criterios para atribuir una cronología tardía, tales como la presencia de apelativos superlativos (pientissimus, piisimus), así como la mención plus minus referida a la edad. Si como veremos ambos usos suelen aparecer en los epitafios fechables en pleno siglo III, su presencia por sí sola no sirve como indicativo de datación tardía, pues en ambos casos los márgenes cronológicos son bastante más amplios.

En todo caso, si atendemos al corpus vadiniense en bloque observamos la repetición de varios elementos que nos permiten proponer una datación de pleno siglo III a un conjunto significativo de estelas. A saber, aquellas que presentan la siguiente estructura: fórmula de consagración $M$ (onumentum) $p$ (ositum) $d$ (is) $m$ (anibus) o $d$ (is) $m$ (anibus) $m$ (onumentum) $p$ (osuit), a la que sigue en primer lugar el dedicante en nominativo y a continuación el difunto en dativo (en muchos casos ambos antropónimos abreviados en tres letras). A veces se completan los epitafios con epítetos superlativos o con la referencia plus minus relativa a la edad. También se observa una relación entre la fórmula final $s$ (it) t(ibi) $t$ (erra) I(evis) con esta centuria, aunque con la particularidad de no estar acompañada por $h$ (ic) $s$ (itus) $e(s t)$, asociación tan frecuente en la epigrafía hispana ${ }^{88}$.

${ }^{85}$ [Monument]um / p [ositum dib]us M/anibus Scorcia O/nnacau(m) Ammiae / Caelionicae ex / gente Penioru(m) / anno(rum) XV / pater filiae / posuit / do(mino) no(stro) Pos(tumo) / IIII et Vict(orino) co(n)s(ulibus) (HEpOL 12049).

${ }^{86} D$ (is) M(anibus) / Val(erio) Quadrato / Boddi filio Vel/lic(ensi) · an(norum) XL · Malc(i)/a · uxsor · Magilo/nis f(ilia) monime/ntu(m) · posuit / Fulvio Pio et Pontio/ [Pr]o[culo Pontiano] (HEpOL 12614).

${ }^{87}$ Conviene recordar que precisamente en Monte Cildá se hallaron los epígrafes funerarios de dos individuos de origo vadiniense, los únicos conocidos hasta el momento muertos fuera del territorium, datados seguramente en el siglo III. Vid. supra n. 23.

${ }^{88}$ En este sentido el profesor J.M. Abascal ha sostenido que el uso de la fórmula sttl sin hse se mantiene en esta zona incluso hasta el siglo IV. (Op. cit., p. 288.) 


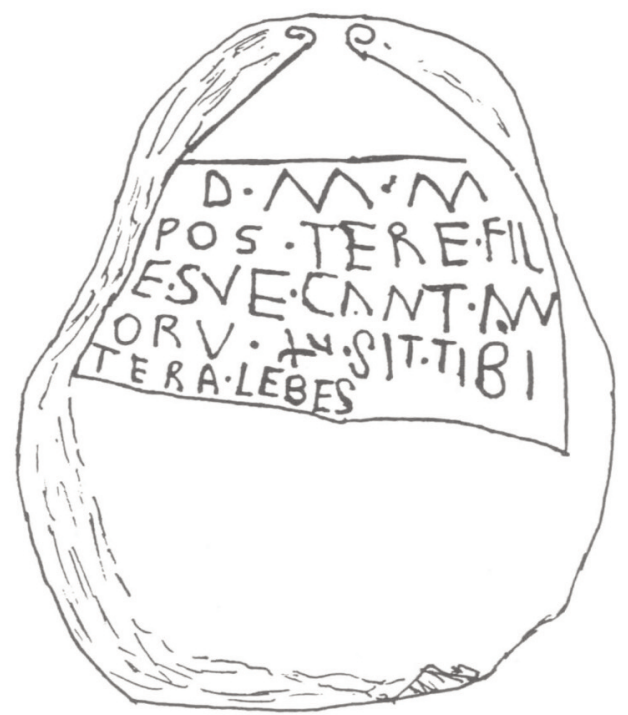

Fig. 7. Estela de Cantia (Coraín) (HEpOL 12055)

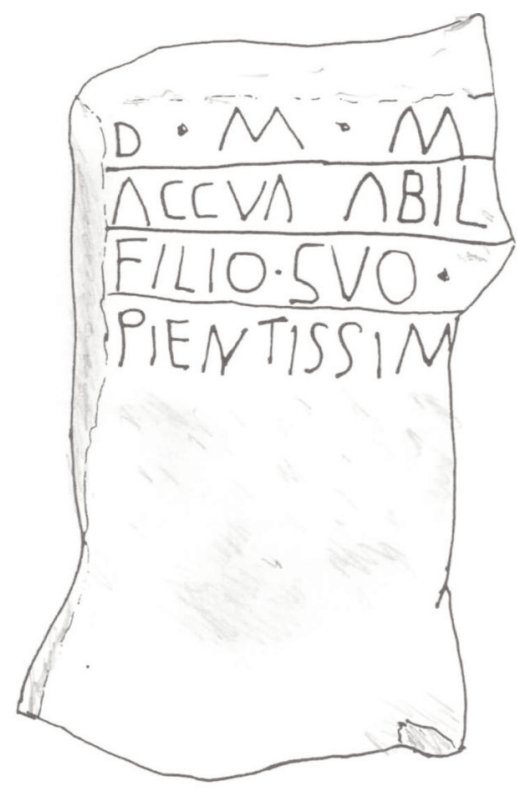

Fig. 8. Estela de Abilius (Anciles) (HEpOL 14523) 
El total de inscripciones que proponemos datar en pleno siglo III asciende a 18, de las cuales 12 son de la parte transmontana y 6 de la cismontana. Con la excepción de los dos ejemplares recuperados en Beleño (Ponga) ${ }^{89}$ y el de Gamonedo (Onís) ${ }^{90}$ (fig. 9), la mayoría de los asturianos se concentra en el término de Cangas de Onís: uno de Coraín ${ }^{91}$ (fig. 7), dos seguros en Corao ${ }^{92}$ más otro probable ${ }^{93}$, uno de Llenín ${ }^{94}$, otro posible en Soto ${ }^{95}$ y uno en Zardón ${ }^{96}$, a los que cabría añadir dos epígrafes muy fragmentarios ${ }^{97}$. En cuanto a la parte leonesa hay dos epígrafes muy claros de Liegos (Acebedo) ${ }^{98}$, uno de ellos del que adjuntamos dibujo (fig. 6), uno de Pedrosa del Rey ${ }^{99}$, el único conocido de Prioro ${ }^{100}$, otro de Anciles (Riaño) ${ }^{101}$ (fig. 8) y posiblemente uno muy fragmentado y deteriorado de Barniedo (Boca de Huérgano) ${ }^{102}$.

${ }^{89} D$ (is) m(anibus) m(onumentum) / Ael(ius) pos(uit) Sep(timio) Sil(oni) / fra(tri) suo Vad(iniensi) / anno(rum) XXXV / s(it) t(ibi) t(erra) I(evis) / En el caballo: L(ucio) Sep(timio) Sil(oni) ben(e) (HEpOL 12048) y $D$ (is) m(anibus) Peregrius / et Pompe(ia) Ar/nunimo/ru(m) / fili(a)e su(a)e pien/ti(s)sim(a)e Supe/[ri(a)e] anno/ru(m) p/lus minus / (a)et(atis) nove (m) (HEpOL 14497).

${ }_{90} D$ (is) m(anibus) m(onumentum) pos(itum) / Dov(iderus) fil(iae) su(a)e / car(ae) Fla(viae) an(norum) XX / c(onsulatu) CCCCXXCII / en el caballo: Fla(via) vin(cas?) (HEpOL 12051).

${ }_{91} D$ (is) m(anibus) m(onumentum) / pos(uit) Tere(ntius) fili(a)/e su(a)e Cant(iae?) an/(n)oru(m) XV sit tibi / tera lebes(!) (HEpOL 12055).

${ }^{92} D$ (is) · M(anibus) $\cdot$ m(onumentum) $\cdot /$ Ter(entius) $\cdot$ Bod(dus) $\cdot$ Va(diniensis) / pos(uit) $\cdot$ matr(i) / sue

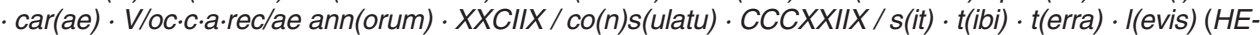
pOL 8540); $D$ (is) m(anibus) m(onumentum) / pos(uit) Ant(onius) Flac(cus) / Vad(iniensis) co(niugi) su(ae) / [Te]r(entiae) Aroni/aecivoru(m) an(norum) XLI / co(n)s(ulatu) CCCXXXIIX / s(it) t(ibi) t(erra) I(evis) (HEpOL 8539).

${ }_{93} D$ (is) M(anibus) / Antoni Pate(rni) / Arreni f(ilii) / Vad(iniensis) Arc/aedun[u(m)] / an(norum) XL Ael(ius) / f(ilio) p(osuit) / s(it) t(ibi) t(erra) I(evis) (HEpOL 8532) Reconstrucción del epitafio por F. Diego (Epigrafía romana de Asturias, Oviedo, 1985, no 50) a partir de dos noticias del siglo XVI.

${ }_{94}$ Pos(uit) An[n]a D(- - ) Vad(iniensis) [m]/ar(ito) suo Dom(itio) Fla(vo) O[rg(enomesco)] an(norum) $L$ / co(n)s(ulatu) CCCX/VI s(it) t(ibi) t(erra) I(evis) (HEpOL 12065). En vista de que la piedra está fragmentada en todo su lado superior, es muy probable que se haya perdido una primera línea con parte de la fórmula de consagración: $D$ (is) m(anibus) m(onumentum).

${ }^{95} D$ (is) m(anibus) / Elanus A/ravi filius / verna Vadi/nienses anno/rum XXIV / Araus pio filio / ob merita/ (sit tibi) t(erra) I(evis) (DIEGO, Francisco, Epigrafía romana..., no 60f).

${ }_{96} \mathrm{M}$ (onumentum) / D(is) m(anibus) / pos(uit) mu(nimentum) / Reburinia / mar(ito) suo / car(o) Flao a/n(norum) LV co(n)s(ulatu) CCC/LXXVII s(it) t(ibi) t(erra) I(evis) (Idem, no 60g).

97 Uno de Abamia: $D$ (is) [m(anibus?)] / pos[uit?- - -] / COIV[- - ] / CARE[- - ] / AMB [ - - ] (HEpOL 12066) y otro de Corao: [- - - ]l v(ixit) an(nos) / [- - - (a)er]a con[s(ulari) - - - / - - ]XXVII / [sit ti]bi terra [levis] (HEpOL 12068).

${ }_{98} D$ (is) M(anibus) m(onumentum) p(osuit) / Aliomus parens / filiae suae pie/ntissimae Mais/ontini(ae) an(norum) p(lus) m(inus) XVIIII (HEpOL 12025) y [D(is)] M(anibus) m(onumentum) p(ositum) / Ces(tius) Fla(- - -) pa(tri) p(osuit) / suo Ces(tio) Bod(do) / Vad(iniensi) an(norum) LXXXV / h(ic) s(itus) t(erra) e(st) (HEPOL 19279).

${ }^{99} D$ (is) ma(nibus) m(onumentum) p(osuit) / Cor(nelius) Mate(rnus) cives / Vad(iniensis) ex pr(aecepto) eor(um) / conviventium / Bodero Sdu/blegino h(eres) ami(co) / suo plu(s) min(us) / an(n)orum XLV // En el caballo SDV(- - -) (HEp 7, 1997, 385=HEpOL 15112).

${ }_{100} \mathrm{D}$ (is) m(anibus) m(onumentum) p(ositum) / Venus Labar[a] / patri suo Alio / Pendiegino / po(suit) m(onumentum) an(norum) XXX (HEpOL 12881).

${ }^{101} D$ (is) m(anibus) m(onumentum) / Accua Abil(io) / filio suo / pientissim[o] (HEpOL 14523). La pieza está partida en la parte derecha, por lo que es muy probable la pérdida de $p$ (osuit) al final de la primera línea.

${ }_{102}$ M(onumentum) p(osuit) / Ambad/us Palar/i n/[- - - / - - / - - ] / XX (HEpOL 12029). 
Para finalizar, recogemos algunas inscripciones muy tardías del foco norte vadiniense, muy posiblemente ya del siglo IV, tales como una de Coraín (Cangas de Onís $)^{103}$, y las de Norenus ${ }^{104}$ y Magnentia ${ }^{105}$ procedentes de Soto de Cangas de Onís, estas últimas catalogadas como cristianas ${ }^{106}$. El análisis cronológico de estas piezas excede el objeto de este trabajo.

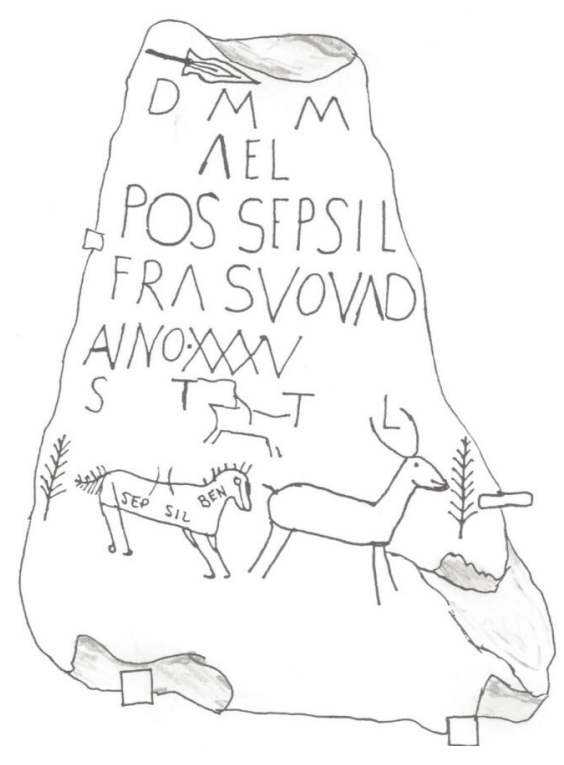

Fig. 9. Estela de Septimius Silo (Beleño)

(HEpOL 12048) (Dibujo del autor)

103 Posuit Sever/a matri suae D/ovidenae an/norum LV ae/ra CCCC/LXXIV (HEpOL 12057).

104 In m(emoriam) s(anctam) mor/tu(u)s a(n)no/ru(m) / septe $(m)$ mise/ravit r(elictos) paren/tes Norenu/s (HEpOL 12058).

${ }_{105}$ Magnen/tia excedit / annoru(m) v/i(gi)nti (!) XXV / ex domu d/ominica (HEpOL 14498).

${ }^{106} \mathrm{Al}$ respecto véase, NAVASCUÉS, J.M., «Trío de estelas...» pp. 151ss. 


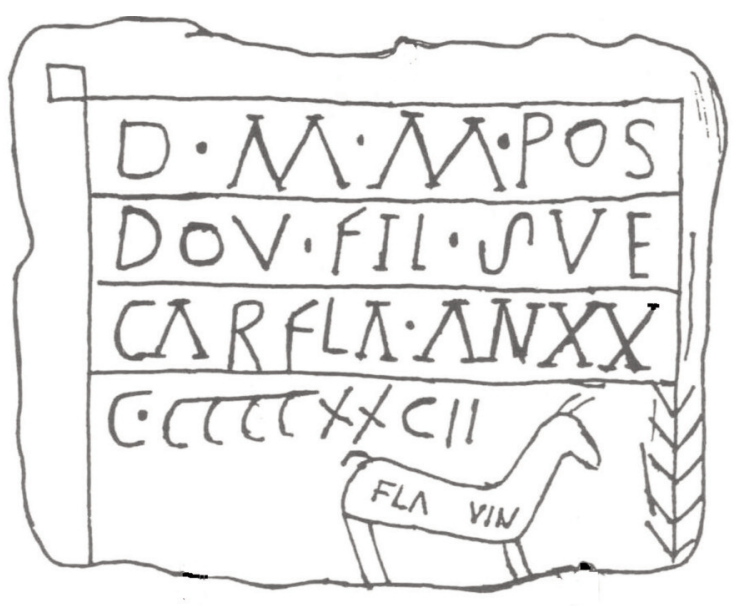

Fig. 10. Estela de Fla(via) (Gamonedo) (HEpOL 12051) (Dibujo del autor)

\section{CONCLUSIONES}

A lo largo de este trabajo hemos revisado al completo la epigrafía funeraria vadiniense, prestando especial atención a los formularios y las estructuras de los textos, con la intención de establecer ciertos indicios y criterios para una definición cronológica. Llegados a este punto es el momento de exponer una síntesis de las principales conclusiones alcanzadas.

En primer lugar es patente lo arduo y poco gratificante que resulta enfrentarse al problema de la datación epigráfica si se pretende conseguir unos resultados incuestionables. A las habituales dificultades con las que se enfrentan los editores de inscripciones hay que añadir las particulares de este conjunto, de manera que ocasiones los argumentos y criterios empleados carecen de la solidez que desearíamos. En cualquier caso, hemos intentado explotar la información contenida en estos textos epigráficos y ofrecer así una propuesta de datación para cada uno de ellos, en muchos casos estableciendo nuevas hipótesis cronológicas.

En cuanto a los resultados obtenidos, una primera conclusión es el aumento de epígrafes fechables en el siglo I, lo que de alguna manera tiende a confirmar la idea de que el hábito epigráfico se inició entre los vadinienses ya en este siglo. Referente al siglo I cabe destacar también la nueva hipótesis de datación para un grupo reducido pero muy homogéneo de epígrafes. Se trata de aquellos que presentan esta sencilla estructura en su epitafio: Munimentum + difunto en genitivo + filiación + Vadiniensis sin abreviar, los cuales proponemos datar en época flavia.

Otra conclusión destacable es la mayor ocurrencia de casos atribuibles al siglo II, hasta el punto de ser la mitad de los contemplados en este estudio. Sostenemos 
que corresponden a este siglo los epitafios encabezados por m(onumentum), a los que sigue el difunto en dativo/genitivo + Vad(iniensi, -is) ya abreviado + dedicante + posuit $+h$ (ic) s(itus) e(st). También pueden ser asignados al siglo II, quizás solo a su segunda mitad, aquellos que presentan una estructura similar a la anterior pero encabezados por $d$ (is) m(anibus) y que no muestran en el epitafio ninguno de los rasgos propios del siglo III. Proponemos por tanto la hipótesis de que el uso de la fórmula $m$ (onumentum) es anterior a $d$ (is) m(anibus).

En lo que respecta a las inscripciones del siglo III, son las más fáciles de datar puesto que contamos con dos paralelos de epitafios fechados por los cónsules epónimos, que a nuestro juicio muestran la relación indudable de la fórmula M(onumentum) $p$ (ositum) $d$ (is) $m$ (anibus) o $d$ (is) m(anibus) m(onumentum) $p$ (osuit) con el siglo III, lo que unido a otros elementos permiten proponer de este siglo a los epitafios que tras esta fórmula de consagración presentan la siguiente estructura: dedicante + difunto en dativo (muchas veces ambos abreviados en tres letras) y que en ocasiones se completa con supelativos, plus minus referente a la edad, mención de origo o la fórmula final $s$ (it) (tibi) t(erra) I(evis). Alrededor de un cuarto de epígrafes pertenecen a este siglo, lo cual sirve indirectamente para rechazar la communis opinio de que una mayoría de inscripciones vadinienses deben fecharse en el siglo III.

\begin{tabular}{|c|c|c|c|c|}
\hline \multicolumn{5}{|c|}{ Tabla 1. Resumen estadístico-cronológico } \\
\hline \multicolumn{2}{|r|}{$\underline{F E C H A}$} & \multicolumn{2}{|c|}{$\begin{array}{c}\text { № DE } \\
\text { EPÍGRAFES }\end{array}$} & $\frac{\text { PORCEN- }}{\underline{\text { TAJE }}}$ \\
\hline \multicolumn{2}{|l|}{ Siglo I } & 8 & \multirow[t]{2}{*}{12} & $17 \%$ \\
\hline \multicolumn{2}{|c|}{ Fines I-inicios II } & 4 & & \\
\hline \multirow[t]{3}{*}{ Siglo II } & inicios & 7 & \multirow[t]{3}{*}{36} & \multirow[t]{3}{*}{$53 \%$} \\
\hline & pleno & 20 & & \\
\hline & $2^{\mathrm{a}}$ mitad & 9 & & \\
\hline \multicolumn{2}{|l|}{ Siglo III } & \multicolumn{2}{|l|}{18} & $26 \%$ \\
\hline \multicolumn{2}{|c|}{ Sin precisar datación (ss. I-III) } & \multicolumn{2}{|l|}{3} & $4 \%$ \\
\hline \multicolumn{2}{|l|}{ TOTAL } & \multicolumn{2}{|l|}{69} & $100 \%$ \\
\hline
\end{tabular}

Por último, somos conscientes de que las dataciones y criterios definidos en este trabajo están sujetos, como no podía ser de otra manera, a revisión, a la espera de que nuevos hallazgos epigráficos, nuevos análisis de los existentes o nuevos planteamientos metodológicos vengan a desechar o confirmar las hipótesis aquí propuestas. 